\title{
A Smaller Habenula is Associated with Increasing Intensity of Sexual Selection
}

\author{
Daniel Hoops ${ }^{\text {a, b, c }}$ Martin J. Whiting ${ }^{d} \quad$ J. Scott Keogh ${ }^{a}$ \\ ${ }^{a}$ Division of Ecology and Evolution, Research School of Biology, The Australian National University, Acton, ACT, \\ Australia; ${ }^{b}$ Mouse Imaging Centre, The Hospital for Sick Children, Toronto, ON, Canada; 'Department of Medical \\ Biophysics, University of Toronto, Toronto, ON, Canada; dDepartment of Biological Sciences, Macquarie University, \\ Sydney, NSW, Australia
}

\section{Keywords}

Brain evolution - Comparative neuroanatomy ·

Lateralization · Reproductive behaviour · Reptiles

\begin{abstract}
The habenula is a small structure in the brain that acts as a relay station for neural information, helping to modulate behaviour in response to variable and unpredictable stimuli. Broadly, it is evolutionarily conserved in structure and connectivity across vertebrates and is the most prominent bilaterally asymmetric structure in the brain. Nonetheless, comparative evolutionary studies of the habenula are virtually non-existent. Here, we examine the volumes of the medial and lateral habenular subregions, in both hemispheres, across a group of Australian agamid lizards in the genus Ctenophorus. In males, we found bilaterally asymmetrical selection on the lateral habenula to become smaller with increasing intensity of sexual selection, possibly as a mechanism to increase aggressive responses. In females, we found bilaterally symmetrical selection on both the medial and lateral subregions to become smaller with increasing sexual selection. This is consistent with sexual selection increasing motivation to reproduce and the habenula's well-character-
\end{abstract}

Karger@karger.com www.karger.com/bbe

Karger!"

BOPEN ACCESS
(C) 2022 The Author(s)

Published by S. Karger AG, Basel

This is an Open Access article licensed under the Creative Commons Attribution-NonCommercial-4.0 International License (CC BY-NC) (http://www.karger.com/Services/OpenAccessLicense), applicable to the online version of the article only. Usage and distribution for commercial purposes requires written permission. ized role in controlling and modifying responses to rewarding stimuli. However, as there are currently no studies addressing habenular function in reptiles, it is difficult to draw more precise conclusions. As has happened recently in biomedical neuroscience, it is time for the habenula to receive greater attention in evolutionary neuroscience.

(C) 2022 The Author(s).

Published by S. Karger AG, Basel

\section{Introduction}

Located in the approximate centre of the brain is a small structure, the habenula, that acts as "coordinator" of sorts for signals being sent from the front of the brain to the back. It filters and sorts information and helps coordinate behavioural responses, especially to complex and unpredictable situations. The internal structure of the habenula and the connections it makes across the brain are, broadly, consistent across vertebrates [Bianco and Wilson, 2009; Aizawa et al., 2011; Freudenmacher et al., 2020].

The role of the habenula appears, broadly, to be one of behavioural flexibility: the ability to modulate and change behaviours in response to dynamic situations and stimu- 
li [Mizumori and Baker, 2017]. It is heavily involved in behavioural responses to positive and negative reinforcement [Schultz, 1998], spatial memory acquisition and retrieval [Lecourtier et al., 2004], maintaining accurate circadian rhythms [Baño-Otálora et al., 2017], sexual and maternal behaviour [Modianos et al., 1974; Malacarne and Vellano, 1982; Matthews-Felton et al., 1995], and even play [van Kerkhof et al., 2013]. These roles are achieved largely through modulating monoamine signalling based on forebrain activity. This has perhaps best been studied in the context of dopamine, but the habenula also modulates the activity of serotonin, norepinephrine, and acetylcholine.

In all vertebrates, the habenula is divided into two subregions; in mammals, birds, and reptiles these are the medial and lateral subregions. The lateral habenula is the more extensively studied of the two regions, primarily (but not exclusively) in mammals. Behaviourally, it is thought to be involved in the ability to generate and modify behavioural strategies to respond to both rewarding and aversive stimuli [Ullsperger and von Cramon, 2003; Matsumoto and Hikosaka, 2007; Boulos et al., 2017; Sosa et al., 2021]. The medial habenula is less well studied but appears to be involved in regulating behaviours such as impulsivity, attention, and fear response [Viswanath et al., 2014]. There also remain many functions, such as those the habenula has in maternal and female sexual behaviour, that have not been identified as more dependent on one subregion.

A striking feature of the habenula is its pronounced bilateral asymmetry across vertebrates. Although not present in every species, there is frequently a volumetric difference between hemispheres in habenular volume [Bianco and Wilson, 2009]. Where this bilateral asymmetry is present, whether the larger habenula is in the left or the right hemisphere varies depending on species, as does whether it is the medial or lateral habenula that is asymmetric. There is currently no consistent explanation as to the functional implications of this asymmetry [Bisazza et al., 1998; Guglielmotti and Cristino, 2006; Stancher et al., 2018], despite it being the most prominent and well-documented volumetric asymmetry in the vertebrate brain.

Among the vertebrate lineages, the habenula is most poorly studied in reptiles. Connectivity studies indicate that the connections formed by the lateral and medial habenulae in reptiles are consistent with those observed in other vertebrates, suggesting that habenula function in reptiles ought to be broadly similar to that observed in other animals [Distel and Ebbesson, 1981; Hoogland, 1982; Díaz and Puelles, 1992]. Like other vertebrates, vol- umetric asymmetry of the habenula is present seemingly haphazardly across reptiles. In some species, the left medial habenula is larger than the right, apparently due to projections from the parietal eye that project only to the left habenula [Engbretson et al., 1981; Korf and Wagner, 1981]; this is currently the only kind of bilateral asymmetry reported in reptile habenulae. Why the projections from the parietal eye result in this kind of asymmetry in some species and not others remains unclear, and whether other forms of bilateral asymmetry, present in other vertebrate groups, are present in reptiles remains unknown.

Studies looking at variation in reptile brain anatomy have used the habenula as a "control" region, measuring it alongside regions that are hypothesized to vary according to a predictor of interest [Crews et al., 1996, 1997; Coomber et al., 1997; Kabelik et al., 2006, 2008; Hews et al., 2012]. This is likely due to the ease of measuring the habenula; its structure is easily discernible from most common nuclear stains. We initially used the left habenula as a control in a previous study examining patterns of sexual dimorphism in the preoptic area and ventromedial hypothalamus in response to the intensity of sexual selection [Hoops, 2016]. However, the study, which was conducted in dragon lizards (Agamidae, Ctenophorus spp.) [Hamilton et al., 2015], unexpectedly found that habenular volume varied with sexual selection. Only the left habenula was measured, however, and it was not subdivided into the medial and lateral subregions. To better understand habenular evolution, and to be able to draw conclusions regarding bilateral asymmetry, here we examine differences in habenular volume in response to the intensity of sexual selection, looking at both the left and right habenulae and both the medial and lateral subdivisions.

\section{Methods}

Animal Acquisition

Two hundred and twelve specimens were collected from the wild in Australia and transported to the Australian National University in Canberra, Australia. Sample sizes per species and sex (male/female) were: Ctenophorus caudicinctus slateri (8/10), C. cristatus (9/7), C. fionni (10/9), C. fordi (10/10), C. gibba (8/6), C. isolepis gularis (10/9), C. modestus (11/7), C. nuchalis (11/3), C. ornatus (8/8), C. pictus (13/10), C. rufescens (10/10), and C. salinarum (9/10). Lizards were maintained in outdoor enclosures with ad libitum access to food (wild insects and supplementary domestic crickets) and water. Specimens were euthanized and perfused according to standard protocol [Hoops, 2015]. Brains, excluding the olfactory bulbs, were extracted from the skulls and stored at $4^{\circ} \mathrm{C}$ until processing. 
Table 1. Averaged phylogenetic linear models

\begin{tabular}{|c|c|c|c|c|c|c|c|c|}
\hline Region & Hemisphere & Factor & Estimate & SE & $\mathrm{RI}$ & Estimate & SE & RI \\
\hline \multirow{3}{*}{ Lateral habenula } & & SDC & -0.194 & 0.098 & 0.44 & & & \\
\hline & & BSSD & -1.791 & 0.848 & 0.46 & -2.566 & 0.778 & \\
\hline & & BSSD & -1.487 & 0.118 & 0.16 & -0.142 & 0.076 & 0.59 \\
\hline \multirow[t]{4}{*}{ Medial habenula } & Left & BV & 0.858 & 0.213 & 1.00 & 1.050 & 0.109 & 1.00 \\
\hline & & SDC & -0.094 & 0.091 & 0.13 & -0.084 & 0.032 & 0.68 \\
\hline & & BSSD & -0.842 & 0.791 & 0.14 & -0.626 & 0.259 & 0.58 \\
\hline & Right & BV & 0.844 & 0.214 & 1.00 & 1.064 & 0.106 & 1.00 \\
\hline
\end{tabular}

Factors in bold are directly correlated with the response variable. Factors in bold italics are inversely correlated with the response variable. $\mathrm{RI}$ values are absent when there is only one model in the set $\triangle \mathrm{AICc} \leq 4$. BSSD, body size sexual dimorphism; BV, brain volume; RI, relative importance; $\mathrm{SDC}$, sexual dichromatism; $\mathrm{SE}$, standard error.

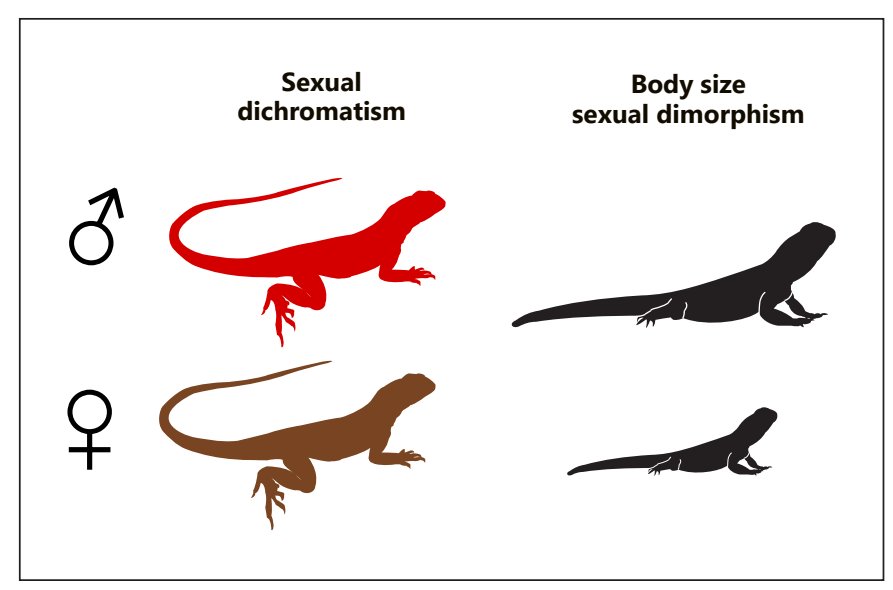

Fig. 1. The two forms of sexual dimorphism used in this study, which have been empirically linked to sexual selection, are differences between males and females in colour (sexual dichromatism) and body size (body size sexual dimorphism).

\section{Habenula Measurement}

Brains were sectioned coronally using a vibratome at $70 \mu \mathrm{m}$ and then stained using the nuclear stain SYBR-green (Life Technologies Australia, Melbourne, VIC, Australia). Images of each section were captured using the image stitching function of the CellSens microscopy platform and a BX63 microscope (Olympus). The areas of both left and right lateral and medial habenulae were measured using the Count \& Measure module in CellSens. Volumes were calculated by multiplying the areas by slice thickness and then summing across slices [Kabelik et al., 2006]. We identified the medial and lateral habenulae by referring to the atlas of the swift dragon (Ctenophorus modestus) brain [Hoops et al., 2018], as well as atlases for other lizard species [Butler and Northcutt, 1973; Cruce, 1974; Medina et al., 1992; ten Donkelaar, 1998]. Measurements were conducted, blind to sex, by a single researcher (D.H.).

\section{Sexual Dimorphism}

The degree of sexual dimorphism in a species, i.e., a phenotypic difference between sexes, is widely associated with the strength of sexual selection [Andersson, 1994; Stuart-Fox and Ord, 2004; Fairbairn et al., 2008; Chen et al., 2012]. In lizards, sexual dimorphism in body size and in colour (sexual dichromatism; Fig. 1) have been empirically linked to the strength of precopulatory sexual selection [Cox et al., 2003; Sullivan and Kwiatkowski, 2007; Fairbairn et al., 2008; Cox and Calsbeek, 2009]. Ctenophorus dragons are among the most variable between species in both these measures [Chen et al., 2012] and are, therefore, an ideal group in which to test the impact of sexual selection on brain evolution. Values for sexual dichromatism and body size sexual dimorphism for the species included here are available from our earlier study [Hoops et al., 2017a]. For each measure, the relative difference between sexes is calculated using the formula $d=2(\mathrm{M}-\mathrm{F}) /(\mathrm{M}+\mathrm{F})$ [Hoops et al., 2017a]. If $d>0$, males are more colourful/larger and if $d<0$, females are more colourful/ larger.

\section{Analysis}

The phylogeny used in this study is pruned from a published phylogeny of agamids [Chen et al., 2012]. Values for whole brain volume, included in our models as a size correction factor, are available from our earlier study [Hoops et al., 2017b]. These values were determined using MRI prior to sectioning and staining each 


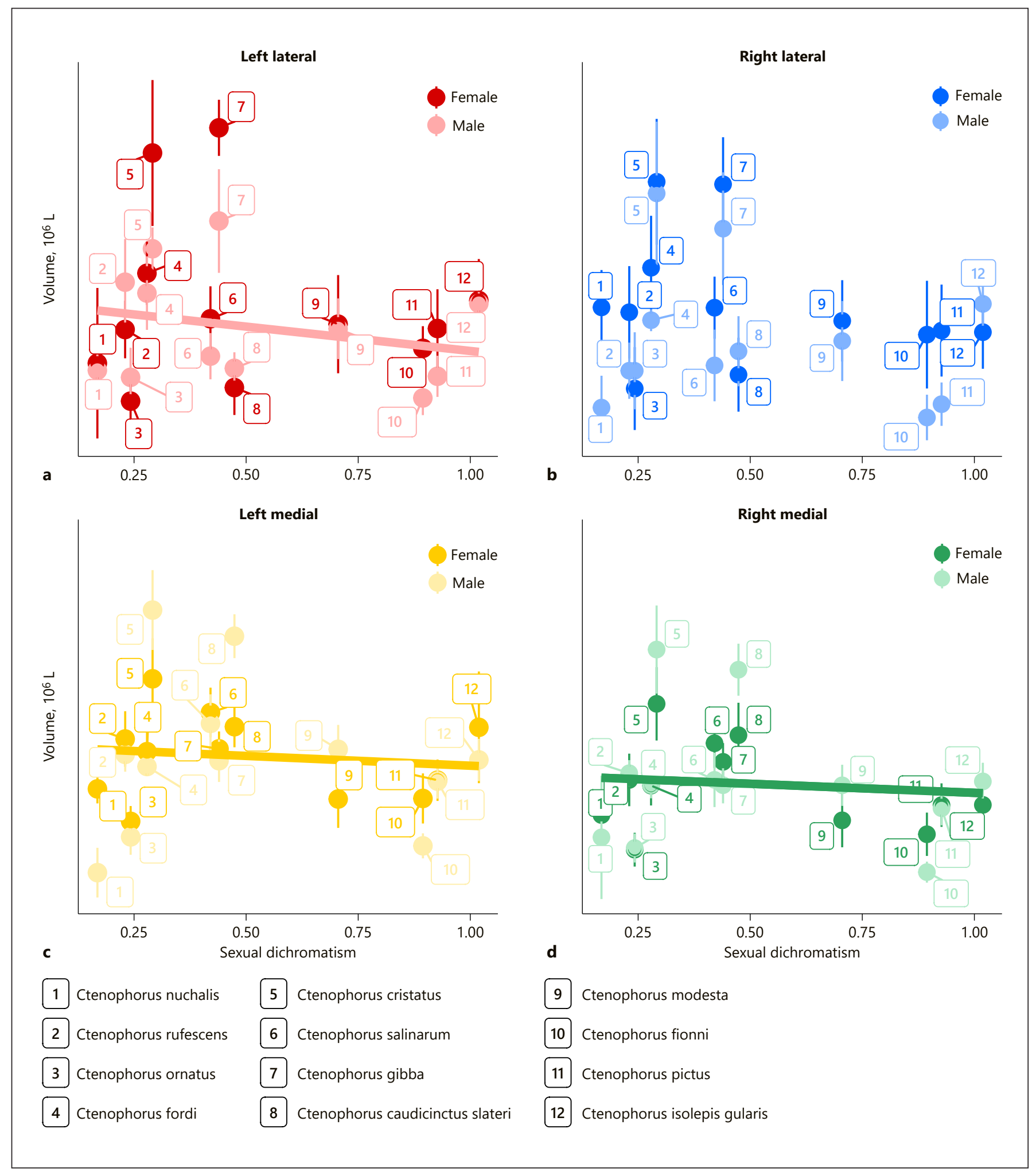

Fig. 2. The mean volumes of the medial and lateral habenulae with respect to increasing levels of sexual dichromatism, an index of sexual selection, in Ctenophorus dragon lizards. The left lateral habenula is negatively correlated with sexual dichromatism in males (a), and both medial habenulae are negatively correlated with sexual dichromatism in females $(\mathbf{c}, \mathbf{d})$. Points show size-independent species means \pm standard error. Regression lines are shown for relationships that have a nonzero slope. 
brain. Volumes were calculated automatically by aligning each brain to an average model of a lizard brain and summing the number of voxels (3D pixels) in the aligned brain-space [Janke and Ullmann, 2015; Hoops et al., 2017b].

For each brain region of interest, left lateral habenula, right lateral habenula, left medial habenula, and right medial habenula, we generated a phylogenetically corrected linear model using the package phylolm [Ho and Ane, 2014] in the computing environment R [R Development Core Team, 2014]. We used Brownian Motion as the evolutionary model as we previously found that it is the most likely model to represent brain evolution in Ctenophorus [Hoops et al., 2017b]. Each model included as independent factors sexual dichromatism, body size sexual dimorphism, and brain volume.

From each model we used the R package MuMIn [Barton, $2014]$ to generate models of all possible combinations of our independent factors and calculate the average of all models in which the corrected Akaike information criterion [Hurvich and Tsai, 1989] was within 4 units of the model with the lowest AICc value [Symonds and Moussalli, 2010; Grueber et al., 2011]. In this model average, predictors were considered significant if their $95 \%$ confidence intervals (CI) did not include 0 . We also report relative importance, a percentage ranking of each factor in a model average that takes into account both the number of models in the average that include the factor, and the quality of those models based on their AICc [Symonds and Moussalli, 2010].

All data and code used here have been deposited at the Open Science Framework (OSF, doi: 10.17605/OSF.IO/8UZNK).

\section{Results}

In the lateral habenula, both sexual dichromatism and body size sexual dimorphism predicted volume to different degrees in both sexes (Table 1). In males, the left lateral habenula decreased in volume with increases in both types of sexual dimorphism (Fig. 2a, 3a). However, the strength of sexual dimorphism and the volume of the right lateral habenula were not significantly related, indicating a bilaterally asymmetric effect (Fig. 2b, 3b). In females, only body size sexual dimorphism was an important predictor of lateral habenula volume (Fig. 2a, b, 3a, b). As body size sexual dimorphism increased, lateral habenula volume decreased, and this effect was consistent across both the left and right lateral habenulae.

The medial habenula showed a relationship with indices of sexual selection only in females (Table 1). Neither form of sexual dimorphism was important for predicting medial habenula volume in males. In females, both body size sexual dimorphism and sexual dichromatism were negatively correlated with medial habenula volume, and this was consistent for both the left and right medial habenulae (Fig. 2c, d, 3c, d).

Sexual Selection and the Habenula

\section{Discussion}

We originally conceived of measuring the habenula because we hypothesized it would not be affected by the intensity of sexual selection and would, therefore, be an appropriate "control" region [Hoops, 2016]. However, we found that there was a relationship between left habenula volume and sexual dichromatism, an index of sexual selection. Based on that finding, we designed this study, separating the habenula into its medial and lateral subregions and measuring them bilaterally. We found that the volumes of both subregions correlated with sexual selection, but differently between sexes. In females, both lateral habenulae and both medial habenulae were smaller in species that were more sexually dimorphic. The lateral habenula correlated with body size sexual dimorphism, while the medial habenula correlated with both indices of sexual selection. In contrast, in males only the left lateral habenula showed a significant correlation with sexual dimorphism; this region was smaller in species that were more dimorphic.

These results are in striking contrast to both the predictions we made previously [Hoops, 2016] and those of other studies, which hypothesized that the habenula is not involved in reproductive (and related) behaviour and is, therefore, an appropriate control region in studies of the neural control of these behaviours [Sakata et al., 2002; Kabelik et al., 2006]. Where a rationale is provided for the use of the habenula as a control, it is that the habenula is not known to express steroid hormone receptors [Coomber et al., 1997; Kabelik et al., 2008]. Indeed, studies of steroid receptor expression and steroid hormone concentration published up to recently validate this rationale: in lizards the habenula is depicted as being devoid of such expression [Morrell et al., 1979; Halpern et al., 1982; Young et al., 1994; Rhen and Crews, 2001; Tang et al., 2001; Rosen et al., 2002]. Furthermore, although functional studies in other vertebrate groups have linked the habenula with reproductive behaviours [Ogawa and Parhar, 2021], no such studies exist for reptiles.

Two more recent studies have demonstrated that there is in fact abundant expression of androgen receptors in the habenula in at least one genus of lizard. The first study found androgen receptor expression exclusively in fibres passing through the habenulae of the Eastern fence lizard (Sceloporus undulatus) [Moga et al., 2000]. Another study found equal or greater numbers of androgen receptorexpressing cells in the habenula compared to the medial preoptic nucleus and ventromedial hypothalamus, two regions traditionally associated with reproductive behav-

Brain Behav Evol 2022;97:265-273 

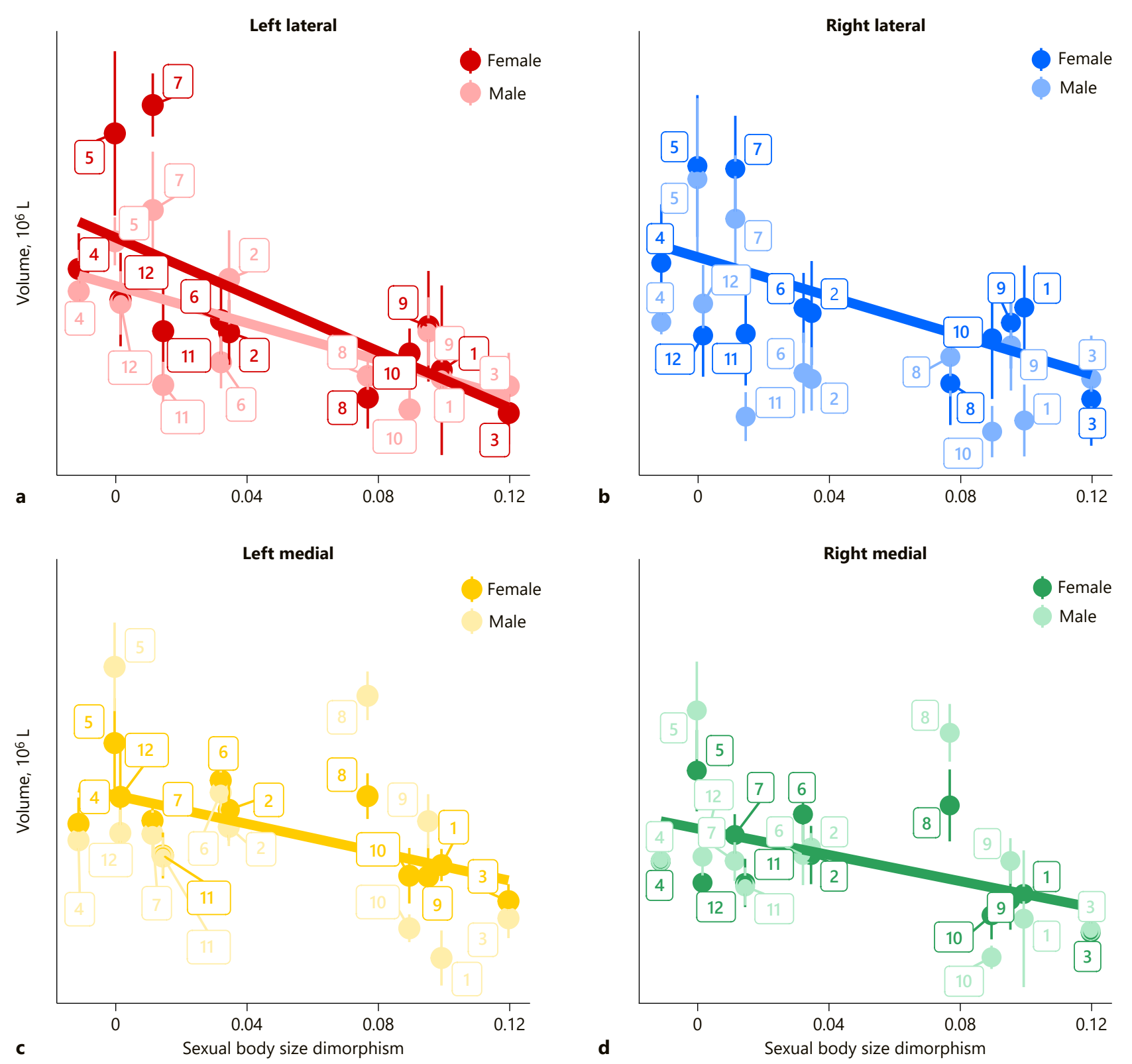

1 Ctenophorus nuchalis

5 Ctenophorus cristatus

2 Ctenophorus rufescens

6 Ctenophorus salinarum

3 Ctenophorus ornatus

7 Ctenophorus gibba

4 Ctenophorus fordi

8 Ctenophorus caudicinctus slateri

9 Ctenophorus modesta

10 Ctenophorus fionni

11 Ctenophorus pictus

12 Ctenophorus isolepis gularis

Fig. 3. The mean volumes of the medial and lateral habenulae with respect to increasing levels of body size sexual dimorphism, an index of sexual selection, in Ctenophorus dragon lizards. The left lateral habenula is negatively correlated with body size sexual dimorphism in both sexes (a), and the right lateral habenula and both medial habenulae are negatively correlated with body size sexual dimorphism in females (b-d). Points show size-independent species means \pm standard error. Regression lines are shown for relationships that have a nonzero slope. 
iour [Hews et al., 2012]. These findings directly contradict not only the earlier work but also each other, as the former detected expression only in fibres, while the latter found expression in cell bodies. This probably reflects the dramatic improvements in antibody binding efficiency and in immunohistochemistry methods that have been developed in the interim. It would be worth recharacterizing steroid hormone receptor expression in the habenula in a broad range of lizard species considering these findings.

The second study mentioned above [Hews et al., 2012] also compared the number of androgen receptor-expressing cells in the habenula of the Eastern fence lizard, which is sexually dichromatic, to that of the sexually monochromatic striped plateau lizard (Sceloporus virga$t u s)$. They found that androgen receptor-expressing cells were more abundant in the monochromatic species, a result which parallels our findings here that habenula volume tends to decrease with increasing sexual dimorphism. The habenula responds to both positive and negative reward, helping control and modify appropriate behavioural responses to diverse stimuli. Increased selection on sexual motivation may effectively require a dampening of motivation and drive to respond to other, diverse stimuli. Under this hypothesis, smaller habenulae and fewer habenular neurons that detect reproductive hormones are outcomes that might be predicted from selection that acts to specifically increase motivation to reproduce.

Interestingly, we found a bilaterally asymmetrical pattern of selection in male dragons. The left lateral habenula was smaller in more dimorphic Ctenophorus species, while the right lateral habenula showed no relationship to sexual dimorphism. The lateral habenula has recently been identified as important for the positive reinforcement of aggressive behaviour in inter-male aggression, at least in mammals [Golden et al., 2016; Flanigan et al., 2017]. Vertebrates, including lizards, are more likely to respond to a conspecific aggressively when viewed through the left eye, a phenomenon known as left-eye preference [Bisazza et al., 1998; Rogers and Andrew, 2002]. In lizards, due to the complete contralateral decussation of optic fibres in the optic chiasm [Butler and Northcutt, 1971], this indicates a preference for aggressive behaviour from the right hemisphere, including the right lateral habenula [Hews and Worthington, 2001]. Aggressive behaviour towards conspecifics is frequently associated with reproduction and mate competition [Cooper et al., 1987; Andersson, 1994; Ariyomo and Watt, 2012; McEvoy et al., 2013], which is a mechanism

Sexual Selection and the Habenula of sexual selection [Baird et al., 1997; Sinervo et al., 2000; Irschick et al., 2007]. Our results suggest, therefore, that sexual selection has acted to increase the relative volume of the right lateral habenula over the left, which is consistent with the role of sexual selection in promoting malemale aggression.

We found more extensive correlations between habenula volume and indices of sexual selection in females. Both habenula subregions, in both hemispheres, were negatively correlated with at least one form of sexual dimorphism. Across vertebrates, sexual selection, and sexual conflict in particular, have well-documented influences on female brain structure in a range of species [Cummings, 2012, 2015, 2018]. However, to our knowledge, this is the first evidence that sexual selection may alter brain structure in female lizards [Hoops et al., 2017a]. In some mammals, the habenula is important for initiating female solicitating behaviours [Modianos et al., 1974, 1975; Matthews-Felton et al., 1995], and in this context it may be important in species with a relatively low intensity of sexual selection or sexual conflict, where we see reductions in brain regions involved in male sexual behaviour [Hoops et al., 2017a]. We note that the slope of the regression lines in the female medial habenulae is shallow, and, therefore, this does not appear to be a strong effect. Nonetheless, this effect, and the potential for sexual selection to alter brain structure in female lizards, deserves additional attention.

In both males and females, it is difficult to draw any strong conclusions regarding the specific behaviours under selection based on our results. Unfortunately, the data we rely on regarding the function of the habenula are necessarily drawn from other vertebrates, principally mammalian model systems. The habenula is measured frequently as a "control" region in lizard neuroscience [Crews et al., 1996, 1997; Coomber et al., 1997; Kabelik et al., 2006, 2008; Hews et al., 2012; Hoops, 2016]; however, studies designed to probe the function of this complex and phylogenetically conserved structure are lacking. As the habenula has received renewed interest in basic and biomedical neuroscience research in the last 20 years [Geisler and Trimble, 2008; Viswanath et al., 2014], we suggest that this region should be a prime target for future studies in evolutionary neuroscience. Its phylogenetically conserved connectivity and structure, its prominent bilateral asymmetry, and the correlation it shows with the intensity of sexual selection indicate that significant advances in understanding this region have the potential to come from further studies in an evolutionary neuroscience context. 


\section{Acknowledgements}

We are grateful for the help and support of the Australian $\mathrm{Na}-$ tional Imaging Facility, Western Sydney University and University of Queensland nodes, for the MRI and image processing assistance that produced the MRI data used in this study. We are also grateful to the Macquarie University Microscopy Unit for the facilities and equipment used for the histology.

\section{Statement of Ethics}

All data used in this study were gathered from experiments that were approved by the Animal Experimental Ethics Committee of the Australian National University (protocol No. A201149).

\section{Conflict of Interest Statement}

Like all academics, the authors of this study are conflicted insomuch as researcher quality, including for funding and employment opportunities, is gauged based on publication output. Other than that, all authors declare no conflicts of interest.

\section{Funding Sources}

This work was supported by grants to D.H. from the National Science and Engineering Council of Canada and The Australian National University; and by grants to M.J.W. and J.S.K. from the Australian Research Council. Funders did not have any direct input into the design, outcomes, or decision to publish this research.

\section{Author Contributions}

This study was conceived and designed by D.H., M.J.W., and S.J.K. D.H. collected and analysed the data and drafted the manuscript. All authors contributed to interpreting the results and editing the manuscript.

\section{Data Availability Statement}

The data and code that support the findings of this study are available at the Open Science Framework (OSF, doi: 10.17605/ OSF.IO/8UZNK).

\section{References}

Aizawa H, Amo R, Okamoto H. Phylogeny and ontogeny of the habenular structure. Front Neurosci. 2011;5:138

Andersson B. Sexual selection. Princeton, NJ: Princeton University Press; 1994.

Ariyomo TO, Watt PJ. The effect of variation in boldness and aggressiveness on the reproductive success of zebrafish. Anim Behav. 2012;83 41-6.

Baird TA, Fox SF, McCoy JK. Population differences in the roles of size and coloration in intra-and intersexual selection in the collared lizard, $\mathrm{Cro}$ taphytus collaris: influence of habitat and social organization. Behav Ecol. 1997;8:506-17.

Baño-Otálora B, Piggins HD. Contributions of the lateral habenula to circadian timekeeping. Pharmacol Biochem Behav. 2017;162:46-54.

Barton K. MuMIn: multi-model inference, version 1.10.5. 2014

Bianco IH, Wilson SW. The habenular nuclei: a conserved asymmetric relay station in the vertebrate brain. Philos Trans R Soc Lond B Biol Sci. 2009;364:1005-20.

Bisazza A, Rogers LJ, Vallortigara G. The origins of cerebral asymmetry: a review of evidence of behavioural and brain lateralization in fishes, reptiles and amphibians. Neurosci Biobehav Rev. 1998;22:411-26.

Boulos L-J, Darcq E, Kieffer BL. Translating the habenula: from rodents to humans. Biol Psychiatry. 2017;81:296-305.

Butler $A B$, Northcutt RG. Retinal projections in Iguana iguana and Anolis carolinensis. Brain Res. 1971;26:1-13.

Butler AB, Northcutt RG. Architectonic studies of the diencephalon of Iguana iguana (Linnaeus). J Comp Neurol. 1973;149:439-62.
Chen I-P, Stuart-Fox DM, Hugall AF, Symonds MRE. Sexual selection and the evolution of complex color patterns in dragon lizards. Evolution. 2012;66:3605-14.

Coomber P, Crews D, Gonzalez-Lima F. Independent effects of incubation temperature and gonadal sex on the volume and metabolic capacity of brain nuclei in the leopard gecko (Eublepharis macularius), a lizard with temperature-dependent sex determination. J Comp Neurol. 1997;380:409-21.

Cooper WE, Mendonca MT, Vitt LJ. Induction of orange head coloration and activation of courtship and aggression by testosterone in the male broad-headed skink (Eumeces laticeps). J Herpetol. 1987;21:96.

Cox RM, Calsbeek R. Sexually antagonistic selection, sexual dimorphism, and the resolution of intralocus sexual conflict. Am Nat. 2009;173: 176-87.

Cox RM, Skelly SL, John-Alder HB. A comparative test of adaptive hypotheses for sexual size dimorphism in lizards. Evolution. 2003;57:165369.

Crews D, Coomber P, Baldwin R, Azad N, Gonzalez-Lima F. Brain organization in a reptile lacking sex chromosomes: effects of gonadectomy and exogenous testosterone. Horm Behav. 1996;30:474-86.

Crews D, Coomber P, Gonzalez-Lima F. Effects of age and sociosexual experience on the morphology and metabolic capacity of brain nuclei in the leopard gecko (Eublepharis macularius), a lizard with temperature-dependent sex determination. Brain Res. 1997;758:169-79.

Cruce JAF. A cytoarchitectonic study of the diencephalon of the tegu lizard, Tupinambis nigropunctatus. J Comp Neurol. 1974;153:215-38.
Cummings ME. Looking for sexual selection in the female brain. Philos Trans R Soc Lond B Biol Sci. 2012;367:2348-56.

Cummings ME. The mate choice mind: studying mate preference, aversion and social cognition in the female poeciliid brain. Anim Behav. 2015;103:249-58.

Cummings ME. Sexual conflict and sexually dimorphic cognition: reviewing their relationship in poeciliid fishes. Behav Ecol Sociobiol. 2018;72: 73.

Díaz C, Puelles L. Afferent connections of the habenular complex in the lizard gallotia galloti. Brain Behav Evol. 1992;39:312-24.

Distel H, Ebbesson SO. Habenular projections in the monitor lizard (Varanus benegalensis). Exp Brain Res. 1981;43:324-9.

Engbretson GA, Reiner A, Brecha N. Habenular asymmetry and the central connections of the parietal eye of the lizard. J Comp Neurol. 1981; 198:155-65.

Fairbairn DJ, Blanckenhorn WU, Szekely T. Sex, size and gender roles: evolutionary studies of sexual size dimorphism. Oxford: OUP; 2008.

Flanigan M, Aleyasin H, Takahashi A, Golden SA, Russo SJ. An emerging role for the lateral habenula in aggressive behavior. Pharmacol Biochem Behav. 2017;162:79-86.

Freudenmacher L, Twickel A, Walkowiak W. The habenula as an evolutionary conserved link between basal ganglia, limbic, and sensory systems: a phylogenetic comparison based on anuran amphibians. J Comp Neurol. 2020;528: $705-28$

Geisler S, Trimble M. The lateral habenula: no longer neglected. CNS Spectr. 2008;13:484-9. 
Golden SA, Heshmati M, Flanigan M, Christoffel DJ, Guise K, Pfau ML, et al. Basal forebrain projections to the lateral habenula modulate aggression reward. Nature. 2016;534:688-92.

Grueber CE, Nakagawa S, Laws RJ, Jamieson IG. Multimodel inference in ecology and evolution: challenges and solutions. J Evol Biol. 2011;24: 699-711.

Guglielmotti V, Cristino L. The interplay between the pineal complex and the habenular nuclei in lower vertebrates in the context of the evolution of cerebral asymmetry. Brain Res Bull. 2006;69: $475-88$.

Halpern M, Morrell JI, Pfaff DW. Cellular [3H]estradiol and $[3 \mathrm{H}]$ testosterone localization in the brains of garter snakes: an autoradiographic study. Gen Comp Endocrinol. 1982;46:211-24.

Hamilton AJ, May RM, Waters EK. Zoology: here be dragons. Nature. 2015;520:42-3.

Hews DK, Hara E, Anderson MC. Sex and species differences in plasma testosterone and in counts of androgen receptor-positive cells in key brain regions of Sceloporus lizard species that differ in aggression. Gen Comp Endocrinol. 2012;176:493-9.

Hews DK, Worthington RA. Fighting from the right side of the brain: left visual field preference during aggression in free-ranging male tree lizards (Urosaurus ornatus). Brain Behav Evol. 2001;58:356-61.

Ho LT, Ane C. A linear-time algorithm for Gaussian and non-Gaussian trait evolution models. Syst Biol. 2014;63:397-408.

Hoogland PV. Brainstem afferents to the thalamus in a lizard, Varanus exanthematicus. J Comp Neurol. 1982;210:152-62.

Hoops D. A perfusion protocol for lizards, including a method for brain removal. MethodsX. 2015;2:165-73.

Hoops D. Structure and evolution of dragon brains. 2016.

Hoops D, Desfilis E, Ullmann JFP, Janke AL, StaitGardner T, Devenyi GA, et al. A 3D MRI-based atlas of a lizard brain. J Comp Neurol. 2018;526: 2511-47.

Hoops D, Ullmann JFP, Janke AL, Vidal-García M, Gardner TS, Dwihapsari Y, et al. Sexual selection predicts brain structure in dragon lizards. J Evol Biol. 2017a;30:244-56.

Hoops D, Vidal-García M, Ullmann JFP, Janke AL, Stait-Gardner T, Duchêne DA, et al. Evidence for concerted and mosaic brain evolution in dragon lizards. Brain Behav Evol. 2017b;90: 211-23.

Hurvich CM, Tsai CL. Regression and time-series model selection in small samples. Biometrika. 1989;76:297-307.

Irschick DJ, Herrel A, Vanhooydonck B, Damme $\mathrm{RV}$. A functional approach to sexual selection. Funct Ecol. 2007;21:621-6.

Janke AL, Ullmann JFP. Robust methods to create ex vivo minimum deformation atlases for brain mapping. Methods. 2015;73:18-26.

Kabelik D, Weiss SL, Moore MC. Steroid hormone mediation of limbic brain plasticity and aggression in free-living tree lizards (Urosaurus ornatus). Horm Behav. 2006;49:587-97.
Kabelik D, Weiss SL, Moore MC. Steroid hormones alter neuroanatomy and aggression independently in the tree lizard. Physiol Behav. 2008;93: 492-501.

Korf H-W, Wagner U. Nervous connections of the parietal eye in adult Lacerta s. sicula Rafinesque as demonstrated by anterograde and retrograde transport of horseradish peroxidase. Cell Tissue Res. 1981;219:567-83.

Lecourtier L, Neijt HC, Kelly PH. Habenula lesions cause impaired cognitive performance in rats: implications for schizophrenia. Eur J Neurosci. 2004;19:2551-60.

Malacarne G, Vellano C. Effects of nostril plugging and of habenulectomy on sexual behaviour in the male crested newt. Behav Process. 1982;7: 307-17.

Matsumoto M, Hikosaka O. Lateral habenula as a source of negative reward signals in dopamine neurons. Nature. 2007;447:1111-5.

Matthews-Felton T, Corodimas KP, Rosenblatt JS, Morrell JI. Lateral habenula neurons are necessary for the hormonal onset of maternal behavior and for the display of postpartum estrus in naturally parturient female rats. Behav Neurosci. 1995;109:1172-88.

McEvoy J, While GM, Sinn DL, Wapstra E. The role of size and aggression in intrasexual male competition in a social lizard species Egernia whitii. Behav Ecol Sociobiol. 2013;67:79-90.

Medina LM, Marti E, Artero C, Fasolo A, Puelles L. Distribution of neuropeptide Y-like immunoreactivity in the brain of the lizard Gallotia galloti. J Comp Neurol. 1992;319:387-405.

Mizumori SJY, Baker PM. The lateral habenula and adaptive behaviors. Trends Neurosci. 2017;40: 481-93.

Modianos DT, Hitt JC, Flexman J. Habenular lesions produce decrements in feminine, but not masculine, sexual behavior in rats. Behav Biol. 1974;10:75-87.

Modianos DT, Hitt JC, Popolow HB. Habenular lesions and feminine sexual behavior of ovariectomized rats: diminished responsiveness to the synergistic effects of estrogen and progesterone. J Comp Physiol Psychol. 1975;89:231-7.

Moga MM, Geib BM, Zhou D, Prins GS. Androgen receptor-immunoreactivity in the forebrain of the eastern fence lizard (Sceloporus undulatus). Brain Res. 2000;879:174-82.

Morrell JI, Crews D, Ballin A, Morgentaler A, Pfaff DW. 3H-Estradiol, 3H-Testosterone and 3HDihydrotestosterone localization in the brain of the lizard Anolis carolinensis: an autoradiographic study. J Comp Neurol. 1979;188:20123.

Ogawa S, Parhar IS. Functions of habenula in reproduction and socio-reproductive behaviours. Front Neuroendocrinol. 2021;64:100964.

R Development Core Team. R: a language and environment for statistical computing. R Foundation for Statistical Computing; 2014.

Rhen T, Crews D. Distribution of androgen and estrogen receptor mRNA in the brain and reproductive tissues of the leopard gecko Eublepharis macularius. J Comp Neurol. 2001;437:385-97.

Rogers LJ, Andrew R. Comparative vertebrate lateralization. Cambridge: Cambridge University Press; 2002.
Rosen G, O’Bryant E, Matthews J, Zacharewski T, Wade J. Distribution of androgen receptor mRNA expression and immunoreactivity in the brain of the green anole lizard. J Neuroendocrinol. 2002;14:19-28.

Sakata JT, Gupta A, Gonzalez-Lima F, Crews D. Heterosexual housing increases the retention of courtship behavior following castration and elevates metabolic capacity in limbic brain nuclei in male whiptail lizards (Cnemidophorus inornatus). Horm Behav. 2002;42:263-73.

Schultz W. Predictive reward signal of dopamine neurons. J Neurophysiol. 1998;80(1):1-27.

Sinervo B, Miles DB, Frankino WA, Klukowski M, DeNardo DF. Testosterone, endurance, and darwinian fitness: natural and sexual selection on the physiological bases of alternative male behaviors in side-blotched lizards. Horm Behav. 2000;38:222-33.

Sosa R, Mata-Luévanos J, Buenrostro-Jáuregui M. The role of the lateral habenula in inhibitory learning from reward omission. eNeuro. 2021 8(3):ENEURO.0016-21.2021.

Stancher G, Sovrano VA, Vallortigara G. Motor asymmetries in fishes, amphibians, and reptiles. Prog Brain Res. 2018;238:33-56.

Stuart-Fox DM, Ord TJ. Sexual selection, natural selection and the evolution of dimorphic coloration and ornamentation in agamid lizards. Proc Biol Sci. 2004;271:2249-55.

Sullivan BK, Kwiatkowski MA. Courtship displays in anurans and lizards: theoretical and empirical contributions to our understanding of costs and selection on males due to female choice. Funct Ecol. 2007;21:666-75.

Symonds MRE, Moussalli A. A brief guide to model selection, multimodel inference and model averaging in behavioural ecology using Akaike's information criterion. Behav Ecol Sociobiol. 2010;65:13-21.

Tang Y, Piao Y, Zhuang L, Wang Z. Expression of androgen receptor mRNA in the brain of Gekko gecko: Implications for understanding the role of androgens in controlling auditory and vocal processes. J Comp Neurol. 2001;438:13647.

ten Donkelaar HJ. Reptiles [Internet]. Springer; 1998. p. 1315-524.

Ullsperger M, von Cramon DY. Error monitoring using external feedback: specific roles of the habenular complex, the reward system, and the cingulate motor area revealed by functional magnetic resonance imaging. J Neurosci. 2003; 23(10):4308-14.

van Kerkhof LWM, Damsteegt R, Trezza V, Voorn $P$, Vanderschuren LJMJ. Functional integrity of the habenula is necessary for social play behaviour in rats. Eur J Neurosci. 2013;38:3465-75.

Viswanath H, Carter AQ, Baldwin PR, Molfese DL, Salas R. The medial habenula: still neglected. Front Hum Neurosci. 2014;7:931.

Young LJ, Lopreato GF, Horan K, Crews D. Cloning and in situ hybridization analysis of estrogen receptor, progesterone receptor, and androgen receptor expression in the brain of whiptail lizards (Cnemidophorus uniparens and C. inornatus). J Comp Neurol. 1994;347:288300 . 